\title{
The citizenship and its relationship with the social responsibility among physical education teachers
}

\author{
Kenioua M. ${ }^{1,2 A B C D E}$ \\ ${ }^{1}$ Institute of Physical Education and Sport University of Ouargla, Algeria \\ ${ }^{2}$ SAMH laboratory University of Mostaganem, Algeria
}

Authors' contributions: A - Study design; B - Data collection; C - Statistical analysis; D - Manuscript Preparation; E - Funds Collection.

$\begin{array}{ll}\begin{array}{l}\text { Abstract } \\ \text { Purpose: }\end{array} & \text { The study aimed to know the level of citizenship and the level of social responsibility among the teachers } \\ \text { of physical education and examine the relationship between the citizenship and the social responsibility. } \\ \text { Material: } & \begin{array}{l}\text { The participants were } 49 \text { physical educations teachers' (male) from middle schools. The citizenship and } \\ \text { the social responsibility scales were used as search tools. } \\ \text { the level of citizenship and social responsibility is high among teachers of physical education, and there } \\ \text { is a positive correlation between citizenship and social responsibility. } \\ \text { Conclusions: }\end{array} \quad \begin{array}{l}\text { To enrich the results of this study it is better to do other studies in the future, such as a comparative study } \\ \text { on citizenship among teachers of physical education in the middle and secondary stage, a study on } \\ \text { citizenship and its relationship to cultural and social background. }\end{array} \\ \text { Keywords: } & \text { citizenship, social responsibility, physical education, teachers, middle schools. }\end{array}$

\section{Introduction}

The concept of citizenship is defined as a systemic concept that refers to fundamental human rights, civil and political rights, social, economic and cultural rights [1]. The concept of citizenship is defined by its linkage to time and space [2], as well as collective rights, they relate to all areas of personal, private, public and political human activity [3]. Affiliation to a homeland means that citizens have full membership, and that there is equal rights and duties between them [4] and consolidating the principle of tolerance and respect despite diversity and difference in custom, religion, thought, financial status and political affiliation [5].

Social responsibility is the commitment of the individual to his / her actions towards society by contributing a range of social activities related to community service [6]. Social responsibility is associated with several concepts including rights and duties, identity and citizenship, ethics and values, individual and collective conscience [7].

It is inconceivable that a society with a whole slice does not fulfil its role at home [8]. It is inconceivable that a society lacks conscience and responsibility towards themselves and those around them, and lacks a sense of community and home issues, believing in the important role and practice of personal, social and legal responsibility is part of the continuation and survival of societies and individuals and the maintenance of their balance $[9,5]$. Society cannot appoint an observer for each individual in the execution of his duties, what is required of him in his work, in the role he plays in serving the society, and in following public order, everyone must have a certain amount of responsibility in the performance of their duty, and do their part before there is accountability or legal question [10]. The sense

(c) Kenioua M., 2020

doi:10.15561/26649837.2020.0202 of citizenship values is the intergenerational struggle over citizenship that every generation has belonging to the homeland more than others [11], and that some people are less belonging to the homeland and this is due to the selfish and individualistic behaviors of many members of the homeland and reluctance to participate seriously in building the homeland, which is represented in the natural environment, human environment and technological environment $[5,7]$.

Teacher of physical education, like other teachers must exercise his affiliation in front of his students and the community [12], emphasizing his identity and proud of his culture and traditions, tolerant, opposed for everything that threatens his identity and doubts his affiliation [13]. Physical education teacher must assume multiple social responsibilities, such as instilling a culture of citizenship for students and raising awareness for the members of the community in which he lives [14], one of his most important roles is to modify and develop students behavior in line with the customs, ethics, and social traditions prevailing in society $[15,16,17]$.

The aim of this study is to know the level of Citizenship and Social responsibility, to investigate relationship between Citizenship and Social responsibility among physical education teachers, no research studies to date have combined this unique set of variables specifically in the field of physical education and sports.

For the purpose of this study, the research study hypotheses were as follows:

HYP.1 There is high level of Citizenship among physical education teachers.

HYP.2 There is high level of Social responsibility among physical education teachers.

HYP.3 There is (positive) correlation relationship between Citizenship and Social responsibility among physical education teachers. 


\section{Material and methods}

Participants

The statistical community in our study represents all teachers of physical education in the middle schools of the city of Ouargla, after conducting the exploratory study on ten (10) teachers (psychometric characteristics) were among the sample to be studied, and after retrieving the questionnaires the number of members of the sample of the basic study were (49) teachers.

Procedure

This field study started in February 2019 until April 2019 ,the researcher distributed the scale of citizenship and social responsibility in the form of a questionnaire based on a set of questions addressed to (59) teachers from the middle schools of Ouargla city, These questionnaires were retrieved in order to carry out the necessary statistical operations (49 questionnaires were returned).

\section{Instruments}

In this study, two scales were used to collect data. The first scale is citizenship was prepared by Labouz [18], the scale consisted 102 items, was distributed according to the Likert type scale, to three dimensions: AIndependence and critical thinking (includes 37 items).BTolerance, solidarity and acceptance of the other (includes 22 items).C- Openness and liberation from political and social hatred (includes 43 items). During the study, the researcher used only dimension A and B they serve the purpose of the study. Cronbach alpha reliability value of the scale was found $(0.80)$. The second scale is social responsibility was prepared by Bakar [19], the scale consisted 78 items, was distributed according to the Likert type scale. Cronbach alpha reliability value of the scale was found (0.92).

\section{Data analyses}

Data analyses were carried out by means of statistical packet for social sciences (SPSS) 25.00 software program. The Mean, Std. Deviation and Pearson Correlation were used in the main study. In addition, alpha-Cronbach was used in the exploratory study.

\section{Results}

Level of citizenship among physical education teachers

In Table 1, it was found that the highest arithmetic mean of citizenship scale was estimated at $(M=2.95)$ at standard deviation $(S D=0.19)$, while the lowest arithmetic mean of citizenship scalewas $(M=1.38)$ at standard deviation $(S D=0.67)$, it was also found that the value of the total arithmetic mean of the citizenship scale was estimated at $(M=2.21)$ with a standard deviation of $(S D 0.16)$, which shows that the level of citizenship is somewhat high among physical education teachers.

Table (02) shows that the highest arithmetic mean of the social responsibility scale was estimated at $(M=3.79)$ at standard deviation $(S D=0.45)$, the lowest arithmetic mean of the social responsibility was $(M=1.93)$ at the standard deviation $(S D=1.19)$, it was also found that the value of the arithmetic mean as a whole of the social

Table 1. Shows the means and standard deviations of theLevel of Citizenship among physical education teachers citizenship scale among physical education teachers

\begin{tabular}{llllllll}
\hline Item & $\mathbf{N}$ & Mean(M) & SD & Item & $\mathbf{N}$ & Mean(M) & SD \\
\hline $\mathbf{1}$ & 49 & 2.51 & .810 & 23 & 49 & 1.93 & .870 \\
$\mathbf{2}$ & 49 & 2.57 & .760 & 24 & 49 & 2.75 & .560 \\
$\mathbf{3}$ & 49 & 2.71 & .610 & 25 & 49 & 1.55 & .790 \\
$\mathbf{4}$ & 49 & 2.87 & .330 & 26 & 49 & 2.20 & .880 \\
$\mathbf{5}$ & 49 & 2.00 & .930 & 27 & 49 & 2.67 & .680 \\
$\mathbf{6}$ & 49 & 2.83 & .470 & 28 & 49 & 2.26 & .860 \\
$\mathbf{7}$ & 49 & 2.85 & .400 & 29 & 49 & 1.38 & .670 \\
$\mathbf{8}$ & 49 & 2.26 & 0.860 & 30 & 49 & 1.57 & .790 \\
$\mathbf{9}$ & 49 & 2.69 & .680 & 31 & 49 & 2.71 & .570 \\
$\mathbf{1 0}$ & 49 & 2.73 & .670 & 32 & 49 & 1.32 & .710 \\
$\mathbf{1 1}$ & 49 & 2.77 & .510 & 33 & 49 & 1.53 & .760 \\
$\mathbf{1 2}$ & 49 & 2.16 & .740 & 34 & 49 & 1.55 & .700 \\
$\mathbf{1 3}$ & 49 & 2.77 & .510 & 35 & 49 & 1.97 & .940 \\
$\mathbf{1 4}$ & 49 & 2.48 & .640 & 36 & 49 & 1.87 & .780 \\
$\mathbf{1 5}$ & 49 & 1.69 & .890 & 37 & 49 & 1.87 & .800 \\
$\mathbf{1 6}$ & 49 & 2.46 & .790 & 38 & 49 & 1.89 & .820 \\
$\mathbf{1 7}$ & 49 & 1.63 & .750 & 39 & 49 & 1.75 & .850 \\
$\mathbf{1 8}$ & 49 & 1.71 & .840 & 40 & 49 & 2.46 & .760 \\
$\mathbf{1 9}$ & 49 & 1.61 & .860 & 41 & 49 & 2.61 & .570 \\
$\mathbf{2 0}$ & 49 & 2.63 & .690 & 42 & 49 & 2.26 & .830 \\
$\mathbf{2 1}$ & 49 & 2.95 & .190 & 43 & 49 & 1.61 & .730 \\
$\mathbf{2 2}$ & 49 & 2.36 & .780 & Total & 49 & 2.21 & .160 \\
\end{tabular}


Table 2. Shows the mean and standard deviations of the social responsibility scale among physical education teachers

\begin{tabular}{llllllllllll}
\hline Item & $\mathbf{N}$ & Mean & SD & Item & $\mathbf{N}$ & Mean & SD & Item & N & Mean & SD \\
\hline 1 & 49 & 3.44 & .810 & 23 & 49 & 3.46 & .910 & 45 & 49 & 3.32 & $\mathbf{1 . 0 0}$ \\
2 & 49 & 3.75 & .590 & 24 & 49 & 3.34 & .960 & 46 & 49 & 2.20 & $\mathbf{1 . 1 5}$ \\
3 & 49 & 3.79 & .570 & 25 & 49 & 3.71 & .640 & 47 & 49 & 3.28 & $\mathbf{1 . 0 2}$ \\
4 & 49 & 3.36 & .830 & 26 & 49 & 3.79 & .570 & 48 & 49 & 3.71 & .610 \\
5 & 49 & 3.65 & .770 & 27 & 49 & 3.79 & .450 & 49 & 49 & 3.61 & .750 \\
6 & 49 & 3.67 & .740 & 28 & 49 & 2.73 & 1.07 & 50 & 49 & 3.65 &. $\mathbf{7 2 0}$ \\
7 & 49 & 3.61 & .860 & 29 & 49 & 2.26 & 1.07 & 51 & 49 & 3.75 & .630 \\
8 & 49 & 3.59 & .810 & 30 & 49 & 3.08 & 1.11 & 52 & 49 & 3.53 & $\mathbf{. 7 9 0}$ \\
9 & 49 & 3.65 & .720 & 31 & 49 & 3.46 & .950 & 53 & 49 & 3.87 &. $\mathbf{3 8 0}$ \\
10 & 49 & 3.51 & .790 & 32 & 49 & 3.18 & .830 & 54 & 49 & 3.67 & .680 \\
11 & 49 & 2.95 & .990 & 33 & 49 & 2.67 & 1.10 & 55 & 49 & 3.75 &. $\mathbf{4 8 0}$ \\
12 & 49 & 3.22 & .790 & 34 & 49 & 3.46 & .950 & 56 & 49 & 2.16 & $\mathbf{1 . 2 1}$ \\
13 & 49 & 3.04 & 1.01 & 35 & 49 & 3.44 & .760 & 57 & 49 & 3.36 & .830 \\
14 & 49 & 3.38 & .780 & 36 & 49 & 3.06 & .960 & 58 & 49 & 3.16 & $\mathbf{1 . 0 8}$ \\
15 & 49 & 3.10 & 1.02 & 37 & 49 & 3.44 & .790 & 59 & 49 & 2.83 & $\mathbf{1 . 2 3}$ \\
16 & 49 & 3.53 & .760 & 38 & 49 & 3.40 & .970 & 60 & 49 & 3.63 & $\mathbf{. 7 2 0}$ \\
17 & 49 & 3.63 & .660 & 39 & 49 & 3.34 & 1.05 & 61 & 49 & 2.53 & $\mathbf{1 . 2 0}$ \\
18 & 49 & 2.83 & 1.02 & 40 & 49 & 1.93 & 1.19 & 62 & 49 & 3.87 & $\mathbf{. 3 8 0}$ \\
19 & 49 & 3.65 & .770 & 41 & 49 & 2.95 & 1.11 & 63 & 49 & 3.67 & $\mathbf{. 5 5 0}$ \\
20 & 49 & 3.67 & .770 & 42 & 49 & 2.20 & 1.02 & 64 & 49 & 3.83 & $\mathbf{. 5 5 0}$ \\
21 & 49 & 3.00 & 1.00 & 43 & 49 & 3.24 & .900 & 65 & 49 & 3.81 & $\mathbf{. 5 2 0}$ \\
22 & 49 & 2.55 & 1.04 & 44 & 49 & 3.12 & .970 & Total & $\mathbf{4 9}$ & $\mathbf{3 . 3 2}$ & .280 \\
\hline
\end{tabular}

Table 3. Shows the Pearson correlation coefficient between the scales of citizenship and social responsibility among physical education teachers

\begin{tabular}{llll}
\hline \multirow{2}{*}{$\begin{array}{l}\text { Citizenship scale social responsibility } \\
\text { scale }\end{array}$} & $\mathbf{N}$ & Correlation coefficient & Significance level \\
\cline { 2 - 4 } & 49 & 0.61 & 0.01 \\
\hline
\end{tabular}

responsibility scale was estimated at $(M=3.32)$ with a standard deviation $(S D=0.28)$. Thus, it was found that the level of social responsibility is somewhat high among physical education teachers.

The relationship between Citizenship and Social responsibility among physical education teachers

It is clear from table (03) that there is a positive correlation between citizenship and social responsibility amongphysical education teachers, where the value of the correlation coefficient Pearson was (0.61) at the level of significance $(0.01)$, meaning that the greater the awareness of the concept of citizenship, the more sense of social responsibility.

\section{Discussion}

In this study, we sought to investigate the level of $\mathrm{f}$ citizenship and social responsibility among physical education teachers, and to know the correlation between citizenship and social responsibility.

As results of this study, it was concluded that the physical education teachers had high level of citizenship, this shows the spirit of patriotism they enjoy, as well as their possession of the values of citizenship and love and ending their homeland and carrying out their duties towards him. It also shows that this category of teachers seeks in various ways and methods to gain and instill such values and others in the personality of the student, it contributes significantly to the preparation of a good citizen in the community to serve his community and his homeland. These findings coincided with the study of Labouz [18] which concluded that the level of citizenship is high among teachers in the intermediate education level, as well as the study carried out by Bouziane [20], which confirmed that the Algerian school contributes effectively in establishing the pillars of citizenship at the level of principle and application. Citizenship or education is not only a set of constitutional texts, laws and articles that define the rights and duties of members of society, individuals must be made aware as citizens, since it is considered a primary point of conducting their activities in daily life.

Results were concluded that the physical education teachers had high level of social responsibility, it is an important characteristic of the teacher, whether it is his responsibility towards the family, or towards the institution in which he works, his colleagues, friends, 
neighbors, and other people who mix with them, towards society in general, or to humanity at large. Cooperation, sacrifice, altruism, love and help of others are behaviors, which reflect on the nature of society and the degree of stability of the positive. These results coincided with the results of Musharraf [21] study, which concluded that students of the Islamic University of Gaza have a high level of social responsibility.

Results were concluded that significant correlation between citizenship and social responsibility. among physical education teachers, the result is logical because the concept of citizenship is reinforced by a sense of social responsibility and the opposite is true; whenever teachers realize the rights and duties of citizenship, this puts on them the burden of the responsibility of the homeland, which shows through their social responsibility, it is the same conclusion reached by Al-Asfoor [22] when he

References

1. Al-Saeed, Muhammad Hamdi. Citizenship and Security. Bahrain: Royal Police Academy. 2013.

2. Glenn E. Citizenship and Inequality: Historical and Global Perspectives. Social Problems. 2000;47(1):1-20. https://doi.org/10.2307/3097149

3. Saif AA. Islamic Sharia and Citizenship Towards the Establishment of the National Community. Political and Strategic Studies; 2009.

4. Sakr Wissam Mohamed Jamil. Political culture and its impacts on the concept of citizenship among young university students in the Gaza strip. [Unpublished thesis]. Gaza University; 2009.

5. Abd Elradi A. Social responsibility and its relationship to citizenship: Social Studies. Istanbul: Egyptian Institute for Studies; 2018.

6. Holmes S. Corporate Social performance and present Areas of Management, Journal of Business, 1985;20:14-20.

7. El-hariti ZBA. The reality of personal social responsibility among Saudi youth and their development. Riyadh: Naiff Arab Academy for Security Sciences; 2001.

8. Fares A, Taili MT. The relationship between attitudes towards the concept of citizenship and social responsibility among the university students: An Empirical Study. Revue des Sciences Sociales et Humaines. [Internet] 2017; 31 [updated $2019 \mathrm{Jul}$ 27; cited 2019 Nov 2]; Available from: https://revues.univouargla.dz/index.php/numero-31-dec-2017-ssh-b/4135-2-2

9. Hamad Z. Citizenship and Social Responsibility, Theoretical Approach. 11th Annual Conference, Social Responsibility and Citizenship, Cairo. National Center for Social and Criminal Research; 2009. P. 120-129.

10.Farag SM. Social and Personal Construction. Alexandria: University Knowledge House; 1989.

11. Gary Hopkins. Teaching citizenship's five themes. [Internet] 1997. [updated 2019 Jul 27; cited 2019 Nov 2]; Available from: http://education-world.com/?reqp=1\&reqr=

12.Laker A. Beyond the Boundaries of Physical Education: Educating Young People for Citizenship and Social examined a survey of citizens' opinions on the factors that increase the sense of citizenship, the most important of these factors is the citizen's capability to shoulder his responsibility towards the country and the other citizen.

\section{Conclusion}

Through the descriptive study about citizenship and social responsibility among physical education teachers in the middle school, which is a sensitive subject considering the changes taking place in the world today in general and the Arab world in particular, it was concluded through the study that the level of citizenship and social responsibility is high among teachers of physical education, and there is a positive correlation between citizenship and social responsibility.

\section{Conflict of interest}

The authors declare that there is no conflict of interest.

Responsibility. New York: Taylor \& Francis e-Library; 2002. https://doi.org/10.4324/9780203135792

13.Ahrari S, Othman J, Hassan M. Role of Social Studies for Pre-Service Teachers in Citizenship Education. International Education Studies. 2013; 6(12): 1-8. https://doi.org/10.5539/ies.v6n12p1

14. Tayoub AA. The values of citizenship among teachers of physical education in intermediate education and its relation to their attitudes towards the curriculum considering the competency approach. [Unpublished PhD Thesis]. University of Ouargla; 2019

15.Shaima ZIM. The role of secondary school teachers in promoting social responsibility among students and ways to develop it in the light of Islamic standards. [Unpublished master Thesis]. University of Gaza; 2014.

16.Abd el-daim AA. Education throughout history. 4 Ed, Beirut: Dar Al Elm for millions; 1981.

17.Anderson LM, Prawat RS. Responsibility in the classroom: A synthesis of researchon teaching self-control. Educational Leadership., 983;40(7): 62-66.

18.Labouz A. The values of citizenship expressed by teachers of social subjects, their relationship with their attitudes towards the curriculum and their motivation to teach. [Unpublished Ph.D. Thesis]. Oran University; 2011.

19.Bakar N. Social responsibility and its relationship to job performance with the faculty, Journal of the College of Basic Education. 2012; 73: 587-567.

20.Bouziane $\mathrm{R}$. The role of the university in the development of the values of citizenship among students, a field study at the University of Kafr El-Sheikh. International Journal of Educational Research, 2006;30: 252-282.

21.Musharraf MM. Ethical thinking and its relationship to social responsibility and some variables among students of the Islamic University of Gaza. [Master Thesis]. Gaza: Faculty of Education, Islamic University; 2009.

22.Al-Asfoor OA. Citizenship and the factors that help increase women in Kuwaiti society, a survey study. Kuwait: Office of Social Development; 2009. 


\section{Information about the author:}

Kenioua M.; http://orcid.org/0000-0002-5405-5723; moukenioua@gmail.com; Institute of Physical Education and Sport, University of Ouargla; SAMH laboratory University of Mostaganem; Mostaganem, Algeria.

Cite this article as:

Kenioua M. The citizenship and its relationship with the social responsibility among physical education teachers. Pedagogy of physical culture and sports, 2020;24(2):59- 63.

https://doi.org/10.15561/26649837.2020.0202

This is an Open Access article distributed under the terms of the Creative Commons Attribution License, which permits unrestricted use, distribution, and reproduction in any medium, provided the original work is properly cited (http://creativecommons.org/licenses/by/4.0/deed.en).

Received: 03.11.2019

Accepted: 24.11.2019; Published: 30.12.2019 